\section{Determination of how As is hosted in pyrite using a combination of LA- ICPMS, TEM, APT, nanoSIMS XAFS, and XANES}

\author{
DANIEL DAVID GREGORY ${ }^{1}$, ANTHONY CHAPPAZ ${ }^{2}$, \\ DANIEL PEREA ${ }^{3}$, SANDRA TAYLOR ${ }^{4}$, JOHN CLIFF $^{3}$ AND \\ LIBOR KOVARIK $^{3}$ \\ ${ }^{1}$ University of Toronto \\ ${ }^{2}$ STARLAB - Earth and Atmospheric Sciences - Central \\ Michigan University \\ ${ }^{3}$ Environmental Molecular Sciences Laboratory, Pacific National \\ Laboratory \\ ${ }^{4}$ Pacific Northwest National Laboratory \\ Presenting Author: daniel.gregory@utoronto.ca
}

Arsenic is a common contaminant in several river systems in the world, both from industrial effluent and natural sources. One of the main natural sources is the oxidation of pyrite. To develop strategies to mitigate the effects of As release due to pyrite oxidation we must understand both the heterogeneity in concentration and redox state of the As in pyrite. This is because whether the As is on the rim rather than center if a pyrite grain will affect when the As is released. Whereas the rate of As release will be affected by the redox state of the As. In this study we investigated two natural pyrite +/-marcasite formations known to oxidize rapidly, one from the Leicester pyrite member in New York and the other from the Black Bute SEDEX deposit in Montana. To determine the heterogeneity in As concentration and redox state of the As in we employed a series of different analytical techniques including laser ablation inductively coupled plasma mass spectrometry (LA-ICPMS), transmission electron microscopy (TEM), atom probe tomography (APT), nanoscale secondary ion mass spectrometry (nanoSIMS), X-ray absorption fine structure spectroscopy (XAFS), and X-ray absorption near edge structure (XANES). Using these techniques we identified wide variation in both where the As was situated in the pyrite and a wide variation in the redox state of the As. Future studies will investigate As release in controlled experiments from the same pyrite samples.

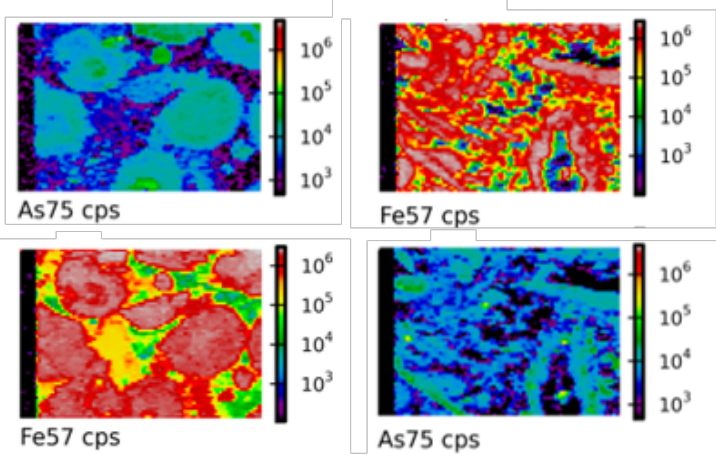

Figure 1: LA-ICPMS trace element maps from the Leicester Pyrite Member (left) and the Black Bute SEDEX deposit (right). Where $\mathrm{Fe}$ is high is where pyrite grains are. Note the variation in As concentration. 